\title{
Optimal rearing medium for the population growth of the predatory mite, Amblyseius swirskii (Athias-Henriot) (Acari: Phytoseiidae)
}

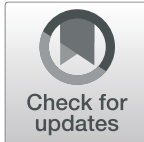

Phyu Phyu San ${ }^{1,2^{*}}$ (D) Midori Tuda ${ }^{3 *}$, Kengo Nakahira ${ }^{3,4}$ and Masami Takagi ${ }^{3}$

\begin{abstract}
Background: The successful rearing of predators or parasitoids is one of the most important elements in biological control programs. The dried fruit mite, Carpoglyphus lactis (L.), can be used as an alternative prey for the phytoseiid predatory mite, Amblyseius swirsOkii (Athias-Henriot).

Main body: This study aimed to evaluate the suitability of 3 different diets for C. lactis when rearing A. swirskii: brown sugar, baker's yeast, and the mixture of brown sugar and baker's yeast along with 3 initial predator:prey ratios (1:7, 1:12, and 1:20). After 30 days, both the baker's yeast and the mixture of brown sugar + baker's yeast diets resulted in the highest predator densities (40.5 times increase at an initial predator:prey ratio of 1:20, with the baker's yeast diet), whereas the mixture diet produced the highest density of prey. The brown sugar resulted in the lowest number of predator and prey mites. This may be due to lower feeding and predation rates of the prey and the predator mites on the brown sugar medium since its relative moisture content and adhesiveness inhibits mite movement. The final predator:prey ratio was also highest on the baker's yeast diet.
\end{abstract}

Conclusions: This study demonstrated that the population growth of A. swirskii was the highest when C. lactis was reared on baker's yeast.

Keywords: Amblyseius swirskii, Carpoglyphus lactis, Baker's yeast, Brown sugar, Diet, Effect on population increase

\section{Background}

Phytoseiid mites are used in biological control programs to suppress pests of greenhouse plants and field crops throughout the world. Among phytoseiid mites, Amblyseius swirskii (Athias-Henriot) (Acari: Phytoseiidae) is currently applied as a highly efficient biological control agent of thrips, whiteflies, and spider mites on ornamental plants and vegetable crops (Calvo et al. 2011). These pests quickly reproduce and are able to establish large populations often resistant to chemical pesticides, making them difficult to control (Herron and James 2007;

\footnotetext{
* Correspondence: linnphyusan@gmail.com; tuda@grt.kyushu-u.ac.jp 'Department of Entomology and Zoology, Yezin Agricultural University, Naypyitaw, Myanmar

${ }^{3}$ Laboratory of Insect Natural Enemies, Institute of Biological Control, Department of Bioresource Sciences, Faculty of Agriculture, Kyushu University, Fukuoka 819-0395, Japan

Full list of author information is available at the end of the article
}

Naveen et al. 2017). Biological control offers economic and environmental benefits by using natural enemies as an alternative strategy of suppressing target pests, besides reducing the negative environmental effects of pesticides.

While the efficiency of predatory mites against target pests is important, rearing protocols also need to be simple and cost-effective. The development of a practical rearing method is a fundamental requirement for controlling serious pests by ensuring a continuous supply of biological control agents (De Clercq 2004). In practice, the production of natural enemies on natural prey (or hosts) is both complicated and expensive due to the logistical requirements of rearing facilities and the need to rear a sufficient amount of prey with a suitable food source. However, because many generalist predators and parasitoids can successfully develop on other species,

\section{Springer Open}

๑ The Author(s). 2020 Open Access This article is licensed under a Creative Commons Attribution 4.0 International License which permits use, sharing, adaptation, distribution and reproduction in any medium or format, as long as you give appropriate credit to the original author(s) and the source, provide a link to the Creative Commons licence, and indicate if changes were made. The images or other third party material in this article are included in the article's Creative Commons licence, unless indicated otherwise in a credit line to the material. If material is not included in the article's Creative Commons licence and your intended use is not permitted by statutory regulation or exceeds the permitted use, you will need to obtain permission directly from the copyright holder. To view a copy of this licence, visit http://creativecommons.org/licenses/by/4.0/. 
rearing cost and complexity might be significantly reduced by substituting natural prey items with alternative prey or factitious hosts (Riddick 2009).

Alternative prey has been used to develop successful rearing systems for phytoseiid mites. For example, Neoseiulus baraki (Athias-Henriot), an important predator of coconut pests, can easily be reared on alternative prey such as the mold mite Tyrophagus putrescentiae (Schrank) in a medium of rice bran and wheat flour (Fernando et al. 2004). Similarly, A. swirskii can be reared on the astigmatid dried fruit mite, Carpoglyphus lactis (Linnaeus) (Acari: Carpoglyphidae) (Fidgett et al. 2010). Astigmatid mites have proven to be suitable alternative prey for $A$. swirskii, which can feed on multiple life stages of these mites. Many species of astigmatid mites have been successfully reared on wheat bran and yeast and used as factitious prey in the mass rearing of predatory mites (Barbosa and de Moraes 2015). However, a predator's performance is generally affected by the nutritional quality of prey, which, in turn, is primarily influenced by the prey's diet. For example, the larval stages of the prey mite, $T$. putrescentiae, reared on a protein-rich and fat-rich diet (dog food), resulted in a high oviposition rate of $A$. swirskii (Pirayeshfar et al. 2020). However, since T. putrescentiae could feed on soft plant tissues and damage crops (Oliveira et al. 2007), it is unsuitable as alternative prey when inoculating the predatory mite in greenhouses or agricultural fields.

Populations of C. lactis increased at higher rates when provided with a diet of white sugar mixed with dry brewer's yeast compared to each diet alone (Matsumoto 1964). While A. swirskii was reared on C. lactis fed on dry yeast (Ji et al. 2015), the optimal diet for C. lactis when rearing $A$. swirskii is unknown.

The purpose of this study was to identify a rearing medium that promotes the highest rate of population growth of the predatory mite $A$. swirskii, feeding on its alternative prey C. lactis.

\section{Materials and methods}

\section{Stock culture of mites}

A culture of the predatory mite A. swirskii (Israeli strain) with $C$. lactis as prey was obtained from Arysta LifeScience Cooperation (Tokyo, Japan). The predatory mite was maintained on $C$. lactis with wheat bran and sugar in a plastic container $(9 \times 4 \mathrm{~cm})$. Prior to the experiment, a colony of $C$. lactis alone was established in another plastic container with a mixture of wheat bran and sugar. Fresh diet was added to each container depending on the population growth of $C$. lactis. If fungi developed in the media, the mites were transferred to a clean container with a fresh diet. The lids of the containers were sealed with parafilm to prevent mites from escaping and contamination by other mites. The A. swirskii cultures were provided with $C$. lactis (along with its diet medium) and inspected every 2 weeks. All cultures were kept in an incubator at $25{ }^{\circ} \mathrm{C}, 70 \% \mathrm{RH}$, and a $16 \mathrm{~h}$ light: $8 \mathrm{~h}$ dark photoperiod. According to previous studies, $A$. swirskii developed from eggs to adults in approximately 7.2 days and laid 16.1 eggs at $25{ }^{\circ} \mathrm{C}$ and $73 \% \mathrm{RH}$, when provided with C. lactis (P. P. San, M. Tuda and M. Takagi, unpublished data). C. lactis developed to adults in 10.1 days and laid 37.3 eggs at $25{ }^{\circ} \mathrm{C}$ and $74 \% \mathrm{RH}$ on a 1:1 mixed diet of white sugar and brewer's yeast (Okamoto 1984).

\section{Experimental rearing of $A$. swirskii and C. lactis}

A variety of different initial predator:prey ratios was used to determine the most suitable medium for A. swirskii reproduction. Mites were reared in ventilated plastic containers $(8 \times 3 \times 5.5 \mathrm{~cm})$, covered with 47 -micron gauze to ensure gas and heat exchange and to prevent the mites' escape. Treatment diets were brown sugar (S), baker's yeast Saccharomyces cerevisiae (Y) (Fig. 1a), and the mixture of brown sugar + baker's yeast diets (SY) (S: $\mathrm{Y}=4: 6$ ) (Fig. 1b). The baker's yeast was in the form of coarse, oblong granules. A preliminary experiment using a mixed diet of brown sugar + brewer's yeast showed a limited increase in both predator and prey densities than the diet of brown sugar + baker's yeast. In the absence of predatory mites, C. lactis populations increased at higher rates on baker's yeast than brewer's yeast. This is because the brewer's yeast was a powdery medium that acted as an adhesive on the legs of $C$. lactis, inhibiting their movement. Therefore, the baker's yeast was used as the diet media instead of brewer's yeast.

Each experimental rearing unit consisted of $2 \mathrm{~g}$ of one of the 3 diet treatments as well as one of 3 initial predator:prey ratios: 1:7 (14 A. swirskii and 98 C. lactis), 1:12 (14 A. swirskii and 168 C. lactis), and 1:20 (14 A. swirskii and 280 C. lactis). Mixed developmental stages of prey were used in all experiments, and the sex ratio of $A$. swirskii was 5:2 (females: males). To set up the experiment, $C$. lactis were first transferred from the stock culture to a rearing unit using a wet camel hairbrush (to prevent injury) and allowed to settle for one day (to become accustomed to the change). Then, 14 adult individuals (10 females and 4 males) of $A$. swirskii were transferred from the stock culture to each rearing unit. Sewing threads were placed in the rearing units to serve as ovipositional sites for $A$. swirskii. Both $A$. swirskii and C. lactis were observed using a binocular microscope. Each treatment (diet medium $\times$ initial predator: prey ratio) was replicated 5 times. The experiment was carried out under the same controlled environmental conditions as the stock culture. After 1 month (30 days), the final predator and prey population densities were estimated by taking five $0.1 \mathrm{~g}$ samples from each rearing unit and 


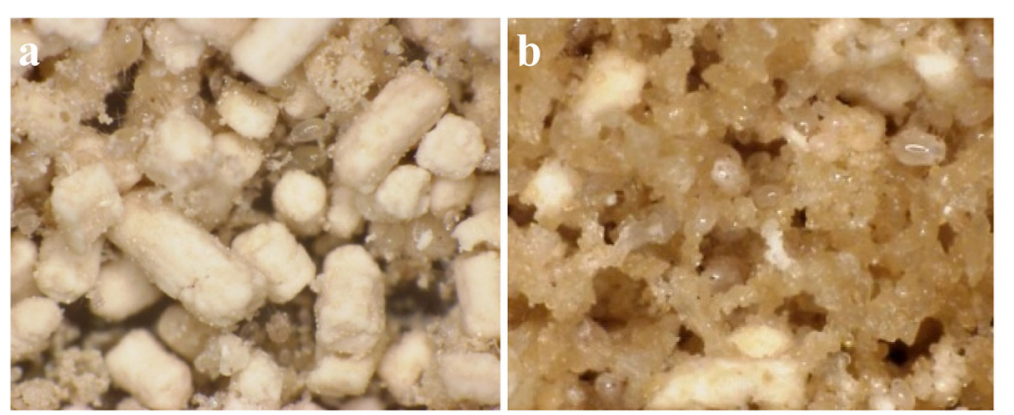

Fig. 1 Rearing medium for the predatory mite, Amblyseius swirskii, and food for its prey, dried fruit mite, Carpoglyphus lactis. a Baker's yeast (and C. lactis) and $\mathbf{b}$ Brown sugar and baker's yeast mixture (and C. lactis)

multiplying the average number of mites to express the population densities per $2 \mathrm{~g}$ of diet medium.

\section{Statistical analysis}

First, the effects of diet, initial predator:prey ratio, and their interaction on the final size of the predator and prey populations (after 1 month of rearing) were analyzed by generalized linear models with a Poisson distribution and a log-link function (Nelder and Wedderburn 1972). Overdispersion of data was corrected. If an effect was significant, a post hoc contrast test was performed. Second, the effects of diet, initial predator:prey ratio, and their interaction on the final predator:(prey +0.5$)$ ratio was tested with a logistic regression model. JMP 13.2.1 (SAS Institute Inc.) was used for all statistical analyses at the significance level $P=0.05$ (Goodman 1993).

\section{Results and discussion}

The diets supplied for $C$. lactis significantly affected the final population densities of $A$. swirskii [likelihood ratio (LR) $\left.X_{2}^{2}=130.51, P<0.0001\right]$ and $C$. lactis $\left(\mathrm{LR} X_{2}^{2}=\right.$ 65.37, $P<0.0001$ ) (Fig. 2). Final densities of $A$. swirskii were significantly higher when prey was supplied by the SY and Y diets, and prey density was significantly higher on the SY diet than on the S and Y diets alone.

In contrast, the initial predator:prey ratio did not affect the final population densities of $A$. swirskii $\left(\right.$ LR $X^{2}{ }_{1}=$ $0.34, P=0.56$ ) or $C$. lactis (LR $X^{2}{ }_{1}=0.02, P=0.90$ ). There was also no significant interaction effect of diet and initial predator:prey ratio on the final population densities of $A$. swirskii (LR $X_{2}^{2}=0.22, P=0.89$ ) or $C$. lactis ( $\operatorname{LR} \chi_{2}^{2}=1.09, P=0.58$ ). The final predator:prey ratio varied among the different diets $\left(\operatorname{LR} X_{2}^{2}=6030.68\right.$, $P=0.0001$ ) but was highest on the $\mathrm{Y}$ diet (Fig. 3). The final predator:prey ratio increased with the initial ratio (LR $\left.X^{2}{ }_{1}=6.06, P=0.01\right)$. There was a significant interaction between diet and initial predator:prey ratio (LR $\chi_{2}^{2}=131.38, P=0.0001$ ).

This experiment showed that higher numbers of $A$. swirskii were produced when prey was provided by the
SY and Y diets. However, the highest prey densities were observed on the SY diet, so the final predator:prey ratio was highest on the $\mathrm{Y}$ diet. Therefore, the $\mathrm{Y}$ diet was the most suitable medium for high rates of $A$. swirskii population growth. Because moisture increased in the SY diet after 2 weeks, this may have disturbed the foraging and reproduction of $A$. swirskii (even though $C$. lactis was still able to reproduce in these conditions). High prey densities might interfere with $A$. swirskii on the SY diet (Chant 1961); additionally, a saturating type II functional response as well as mutual interference by $A$. swirskii itself (Fathipour et al. 2020) may limit oviposition rates and fecundity (Nakamichi et al. 2020). In this study, $A$. swirskii populations (both males and females) increased 40.5 times after 30 days without additional prey at an initial predator:prey ratio of 1:20, on the baker's yeast diet. In a previous study, with the same initial number of females and predator:prey ratio, the female-only population increased 21.5 times after $24+4$ days when provided with an additional supply of prey (Ji et al. 2016). While it is difficult to compare these 2 studies because of differences in methodology and unreported sex ratios, this combination of dietary resources and prey appears to support sufficiently high rates of reproduction and survival for the predatory mite $A$. swirskii.

C. lactis exhibited a higher population growth on the $\mathrm{S}$ diet than on a diet of white sugar because of the higher water and nitrogen contents of the S diet (Iimuro 1956). The relatively low densities of both mites on the $S$ diet during this study may be due to the nutrient content of the $\mathrm{S}$ diet, which was too poor for $C$. lactis (so the predator could not find enough prey), or because the $S$ medium was too sticky for both mites to successfully forage and reproduce. While $C$. lactis can be reared on the Y diet alone (baker's yeast, Chmielewski 1971), an SY mixture was optimal (4:6 ratio of white sugar and brewer's yeast, Matsumoto 1964 and Okamoto 1984). Baker's yeast is available in several different forms; coarse, oblong granules of dry yeast was used in this study. This form served as a porous medium and 


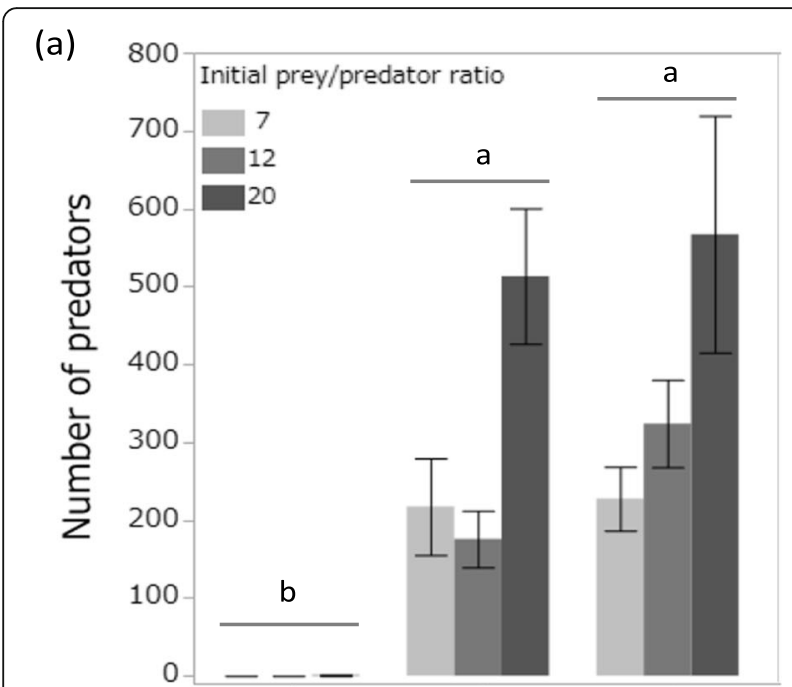

(b)

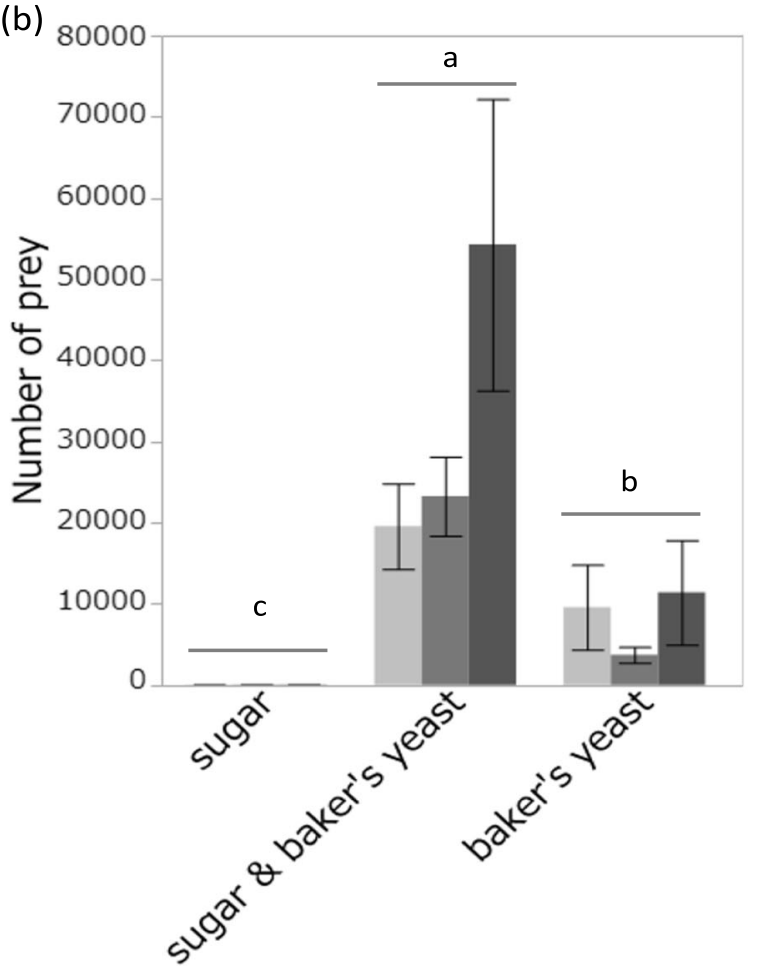

Fig. 2 Mean numbers ( \pm SE) of a Predatory mites Amblyseius swirskii and $\mathbf{b}$ Prey mites Carpoglyphus lactis reared on different diets at different initial predator:prey ratios for a month (30 days). Same letters indicate that means are not significantly different $(P>0.05)$

allowed free movement of both mites and provided sufficient nutrition for $C$. lactis. Therefore, the $\mathrm{Y}$ diet (baker's yeast) was a suitable diet for $C$. lactis when rearing A. swirskii.

Rearing programs that involve factitious hosts can reduce the complexity and cost of producing biological control agents. Even though the predatory mite A. swirskii can reproduce on pollen, the collection of pollen is a

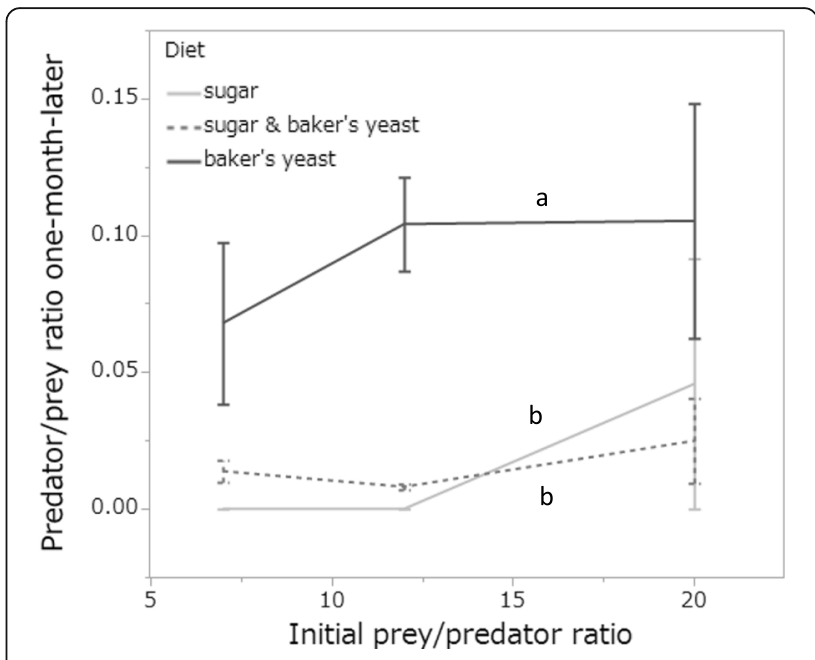

Fig. 3 Predator:prey ratio (mean \pm SE) of mites after one month (30 days) of rearing on different diets at different initial predator:prey ratios. Same letters indicate that means are not significantly different

laborious process and A. swirskii reared on cattail pollen do not reproduce as well as those provided with $C$. lactis (Nguyen et al. 2013). Moreover, when the rearing hosts themselves are crop pests, there can be a risk of spreading them along with the control agent when they are used in the mass culture of natural enemies. For instance, this became a problem in Spain when rearing Eretmocerus mundus (Mercet) on the $\mathrm{Q}$ strain of the whitefly Bemisia tabaci (Gennadius) (Van Driesche et al. 2008). However, the dried fruit mite C. lactis, which was used as an alternative prey in this study, did not damage crops.

\section{Conclusion}

The baker's yeast is a suitable (but not optimal) diet for the prey mite $C$. lactis and an optimal medium for the predatory mite A. swirskii. An additional benefit is that baker's yeast is a relatively low-cost material. This study highlighted the high population increase of the predatory mite A. swirskii when provided with the prey mite C. lactis in a medium of baker's yeast alone. This efficient rearing method can be applied safely and effectively as a shortterm method for maintaining populations of $A$. swirskii.

\section{Abbreviations}

S: Brown sugar; Y: Baker's yeast; SY: Brown sugar and baker's yeast mixture; $\mathrm{RH}$ : Relative humidity; LR: Likelihood ratio; $X^{2}$ : Chi-square

\section{Acknowledgements}

We thank Japan International Cooperation Centre (JICE) for providing financial support and J. Miksanek for comments.

\section{Authors' contributions}

PPS conducted the experiment and wrote the original manuscript. M Tuda analyzed the data, prepared the figures, and revised the final version of the manuscript. M Tagaki and KN supervised the experiment. All authors have approved the final version of the manuscript. 


\section{Funding}

There is no financial or other dependencies between authors and any of the companies considered.

\section{Availability of data and materials}

The datasets used during the current study are available from the corresponding author on reasonable request.

\section{Ethics approval and consent to participate}

All applicable international, national, and/or institutional guidelines for the care and use of animals were followed. This article does not contain any studies with human participants or vertebrates performed by any of the authors.

\section{Consent for publication}

Consent for publication was obtained from all individual participants included in the study.

\section{Competing interests}

All authors declared that they have no conflict of interest.

\section{Author details}

${ }^{1}$ Department of Entomology and Zoology, Yezin Agricultural University, Naypyitaw, Myanmar. 'Laboratory of Insect Natural Enemies, Graduate School of Bioresource and Bioenvironmental Sciences, Kyushu University, Fukuoka 819-0395, Japan. ${ }^{3}$ Laboratory of Insect Natural Enemies, Institute of Biological Control, Department of Bioresource Sciences, Faculty of Agriculture, Kyushu University, Fukuoka 819-0395, Japan. ${ }^{4}$ Laboratory of Agricultural Entomology, Department of Sustainable Agriculture, College of Agriculture, Food and Environmental Sciences, Rakuno Gakuen University, Bunkyodai-Midorimachi, Ebetsu, Hokkaido, Japan.

Received: 16 July 2020 Accepted: 7 October 2020

Published online: 19 October 2020

\section{References}

Barbosa MF, de Moraes GJ (2015) Evaluation of astigmatid mites as factitious food for rearing four predaceous phytoseiid mites (Acari: Astigmatina; Phytoseiidae). Biol Control 91:22-26

Calvo FJ, Bolckmans K, Belda JE (2011) Control of Bemisia tabaci and Frankliniella occidentalis in cucumber by Amblyseius swirskii. BioControl 56(2):185-192

Chant DA (1961) The effect of prey density on prey consumption and oviposition in adults of Typhlodromus (T.) occidentalis Nesbitt (Acarina: Phytoseiidae) in the laboratory. Can J Zool 39(3):311-315

Chmielewski W (1971) Morphology, biology and ecology of Carpoglyphus lactis (L., 1758) (Glycyphagidae: Acarina). Prace Nauk Inst Ochr Roślin 13(2):63-166

De Clercq P (2004) Culture of natural enemies on factitious foods and artificial diets. In: Capinera JL (ed) Encyclopedia of entomology, vol 1. Kluwer Acad Publ, Dordrecht, The Netherlands, pp 650-652

Fathipour Y, Maleknia B, Bagheri A, Soufbaf M, Reddy GVP (2020) Functional and numerical responses, mutual interference, and resource switching of Amblyseius swirskii on two-spotted spider mite. Biol Control 146(2020):104266

Fernando LCP, Aratchige NS, Kumari SLML, Appuhamy PALD, Hapuarachchi DCL (2004) Development of a method for mass rearing of Neoseiulus baraki, a mite predator on coconut mite, Aceria guerreronis. COCOS 16:22-36

Fidgett MJ, Stinson A, Clacton L, Stewart C, Stinson A (2010) Method for rearing predatory mites. US patent 2010/0119645 A1

Goodman SN (1993) P value hypothesis and likelihood: implications for epidemiology of a neglected historical debate. Am J Epidemiol 137:485-496

Herron GA, James TM (2007) Insecticide resistance in Australian populations of western flower thrips, Frankliniella occidentalis Pergande (Thysanoptera: Thripidae). Gen Appl Ent 36:1-5

limuro I (1956) Studies on acaroid mites. II. Observation on the growth requirements of the sugar- mite, Carpoglyphus lactis (Linnaeus, 1758). Med Entomol Zool 7(3.4):183-189

Ji J, Zhang YX, Lin JZ, Chen X, Sun L, Saito Y (2015) Life history of three predatory mites feeding upon Carpoglyphus lactis (Acari, Phytoseiidae; Carpoglyphidae). Syst Appl Acarol 20(5):491-496

Ji J, Zhang YX, Saito Y, Takada T, Tsuji N (2016) Competitive and predacious interactions among three phytoseiid species under experimental conditions (Acari: Phytoseiidae). Environ Entomol 45(1):46-52
Matsumoto K (1964) Studies on the environmental factors for the breeding of grain mites. V. comparison of the breeding rate of Carpoglyphus lactis and Tyrophagus dimidiatus. Med Entomol Zool 15:17-24

Nakamichi Y, Tuda M, Wajnberg E (2020) Intraspecific interference between native parasitoids modified by a non-native parasitoid and its consequence on population dynamics. Ecol Entomol:45. https://doi.org/10.1111/een.12909

Naveen NC, Rahul C, Kumar D, Reb KB, Rajagopal R (2017) Insecticide resistance status in the whitefly, Bemisia tabaci genetic groups Asia-I, Asia-II-1 and AsiaII-7 on the Indian subcontinent. Sci Rep 7:40634

Nelder J, Wedderburn R (1972) Generalized linear models. J Roy Stat Soc A 135(3):370-384

Nguyen DT, Vangansbeke D, Lü X, de Clercq P (2013) Development and reproduction of the predatory mite Amblyseius swirskii on artificial diets. BioControl 58:369-377

Okamoto M (1984) Studies on the environmental factors for the life cycle of Carpoglyphus lactis.1. The effects of relative humidities on individual rearing. Med Entomol Zool 35:269-275

Oliveira CMD, Návia D, Frizzas MR (2007) First record of Tyrophagus putrescentiae (Schrank) (Acari: Acaridae) in soybean plants under no tillage in Minas Gerais, Brazil. Ciênc Rural 37(3):876-877

Pirayeshfar F, Safavi SA, Moayeri HRS, Messelink GJ (2020) The potential of highly nutritious frozen stages of Tyrophagus putrescentiae as a supplemental food source for the predatory mite Amblyseius swirskii. Biocontrol Sci Technol 30: 403-417

Riddick E (2009) Benefits and limitations of factitious prey and artificial diets on life parameters of predatory beetles, bugs and lacewings: a mini- review. BioControl 54:325-339

Van Driesche R, Hoddle M, Center T (2008) Control of pests and weeds by natural enemies: an introduction to biological control. Blackwell, USA

\section{Publisher's Note}

Springer Nature remains neutral with regard to jurisdictional claims in published maps and institutional affiliations.

\section{Submit your manuscript to a SpringerOpen ${ }^{\circ}$ journal and benefit from:}

- Convenient online submission

- Rigorous peer review

- Open access: articles freely available online

- High visibility within the field

- Retaining the copyright to your article

Submit your next manuscript at $\boldsymbol{\nabla}$ springeropen.com 